Iran Journal of Nursing (IJN)

Vol 34, No. 131, Aug 2021: 70- 81

\title{
Effect of Self-care Education on the Functional Status of Patients with Rheumatoid Arthritis
}

\author{
Alireza Baratzadeh ${ }^{1}$, Zahra Kashaninia ${ }^{2}$, Fatemeh Mohaddess ${ }^{3}$, Mohammad Hasan Jokar ${ }^{4}$, \\ Shima Haghani ${ }^{5}$
}

\begin{abstract}
Background \& Aims: Rheumatoid arthritis is an autoimmune disease with a chronic and progressive nature. It starts with periods of inflammation in the synovium, and causes it to be thicken resulting in edema in the synovial tissue. It affects $1 \%$ of people worldwide, but its prevalence varies among different regions, different races, and different groups of people. Like other chronic diseases, this disease not only has no definitive cure, but also leads to a severe decline in the performance of the affected people and a decrease in independence in performing their daily activities. Studies show that structured educational approaches about self-care can improve the performance and health of patients with chronic diseases such as rheumatoid arthritis. Accordingly, individuals must learn the knowledge and skills needed to make decisions, solve their problems, and communicate with others. Self-care education in these patients helps them to reach a level of health where they not only feel satisfaction with their personal life, but also can contribute effectively and significantly to the community as a citizen. Therefore, encouraging patients to adopt appropriate self-care behaviors is an important factor in the management of rheumatoid arthritis. People with high levels of self-care have more access to health care, experience shorter periods of hospitalization, and subsequently less complications caused by hospitalization in these centers. Without education and patients' participation in the self-care process, health care programs will be more expensive and the patient's quality of life will be reduced. Thus, self-care education along with other treatment and rehabilitation processes seems necessary in patients with rheumatoid arthritis. Despite the importance of self-care, studies suggest that patients with rheumatoid arthritis have little knowledge and information about their disease and selfcare methods, and lack of knowledge leads to frequent recurrence of the disease and an increase in the frequency of their hospitalizations. Likewise, there is a gap in the studies about education of affected people and few studies have investigated this issue. Therefore, the researcher decided to conduct a study to evaluate the effectiveness of self-care education on the functional status of people with rheumatoid arthritis.

Materials \& Methods: This is an evaluation and single group study conducted on 40 patients with rheumatoid arthritis, and evaluated the effect of self-care education on functional status of patients with rheumatoid arthritis. The sampling process continued from October 2019 to February 2020 among patients hospitalized in the rheumatology wards of Imam Reza and Ghaem educational-research center and treatment centers in Mashhad. Before the intervention, the samples were asked to complete demographic and functional status questionnaire. They also completed the form of informed consent and the researcher ensured that their information would remain confidential. Five 25-minute self- care educational sessions were held for samples individually and at their bedside every other day. The researcher was responsible for holding educational sessions and presenting educational contents. Two weeks after the last educational session, functional status questionnaire was performed again to

\footnotetext{
1. Department of Internal Medicine and Surgery, School of Nursing and Midwifery, Iran University of Medical Sciences, Tehran, Iran

${ }^{2}$. Nursing Care Research Center, Department of Pediatric and Psychiatric Nursing, School of Nursing and Midwifery, Iran University of Medical Sciences, Tehran, Iran $\quad$ (Corresponding author) Tel: 09121592900 Email: kashaninia.za@iums.ac.ir

3. Department of Internal Medicine and Surgery, School of Nursing and Midwifery, Iran University of Medical Sciences, Tehran, Iran

4. Department of Rheumatology, School of Medicine, Mashhad University of Medical Sciences, Mashhad, Iran
}

5. Biostatistics, Nursing Care Research Center, Iran University of Medical Sciences, Tehran, Iran
\end{abstract}


record the patients' function scores in different areas after the intervention. After the data collection process, data were analyzed using statistical tests in SPSS 16. Frequency and percentage were used for qualitative variables and numerical indices including minimum, maximum, mean, and standard deviation were used for quantitative variables. Paired t-test was used for inferential statistics for comparison before and after the intervention.

Results: This study included 40 patients with rheumatoid arthritis hospitalized in rheumatology wards of Imam Reza and Ghaem hospitals. The Findings showed that the mean age of the samples was $45.72 \pm 9.77$ years, most samples (\%70) were female, married (\%87.5), housewives (\%57.5), had a diploma and lower degrees (90\%), and $55 \%$ reported an underlying disease. Most of them (\%62.5) had rheumatoid arthritis for five years and less. Table 1 shows these findings. The results of $t$-test revealed that the score of activities of daily living $(\mathrm{P}<0.001)$, basic activities of daily living $(\mathrm{P}<0.0001)$, psychological function $(\mathrm{P}=0.001)$, job function $(\mathrm{P}<0.001)$, and social activities $(\mathrm{P}=0.002)$ increased significantly after the intervention. However, the increase in the dimension of the quality of social interaction was not significant $(\mathrm{P}=0.77)$. In terms of tool cut point, the findings showed that the mean score of activities of daily living was at warning zone before the intervention for all samples, but after the intervention, (15.0\%) showed good performance. In activities of daily living, before intervention all samples were at the warning zone but after the intervention, (12.5\%) had a good performance. In terms of psychological function, before the intervention, $80 \%$ of the samples were at warning zone, but after the intervention, $(25 \%)$ showed good performance and (75\%) were at the warning zone. In job function dimension, all patients were at warning zone before the intervention, but after the intervention, (10\%) had good performance. In social function dimension, $95 \%$ of the subjects were at the warning zone. After the intervention, $(75 \%)$ were at warning zone and $(25 \%)$ showed good function. In quality of social interactions dimension, before the intervention, $(85.0 \%)$ were at the warning zone and after the intervention, (72.5\%) of the subjects were at the warning zone and $(27.5 \%)$ showed good performance.

Conclusion: The results of the present study indicated that a self-care education approach plays an effective positive role in the treatment and rehabilitation of people with rheumatoid arthritis and these programs can be used as a part of the healing process of these patients along with other treatment and rehabilitation processes. In addition, the research hypothesis concerning the positive effect of self-care education on the functional status of people with Rheumatoid Arthritis was confirmed using the research data. There was no statistically significant increase in the quality of social interactions, which may require more time, and it is suggested that future studies devote more time to examining changes. Also, using more specialized educational contents for quality of social interaction can improve and enhance the results of educational process in this area of functional status of rheumatoid arthritis patients.

Keywords: Rheumatoid Arthritis, Patient Education, Self-care, Activity of Daily Living.

\section{Conflict of Interest: No}

How to Cite: Baratzadeh A, Kashaninia Z, Mohaddess F, Jokar MH, Haghani SH. Effect of Self-care Education on the Functional Status of Patients with Rheumatoid Arthritis. Iran Journal of Nursing. 2021; 34(131):70-81.

Received: 15 May 2021

Accepted: 16 Aug 2021 


\title{
ارزشيابى اثر آموزش خود مراقبتى بر وضعيت عملكرد افراد مبتلا به آرتريت روماتوئيد
}

\author{
عليرضا برات زاده '، زهرا كاشانى نيا؟، فاطمه محدث"، محمد حسن جوكارعُ، شيما حقانى
}

\begin{abstract}
جكيده
زمينه و هدف: آرتريت روماتوئيد از جمله بيمارىهاى خود ايمنى، و سير مزمن و بيشرونده دارد. منجر به افت شديد عملكرد افراد مبتلا و كاهش

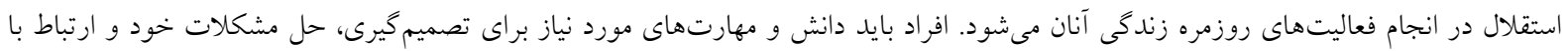

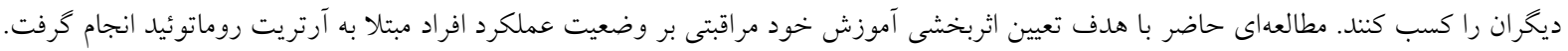

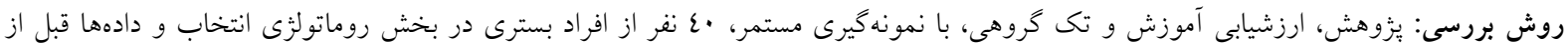

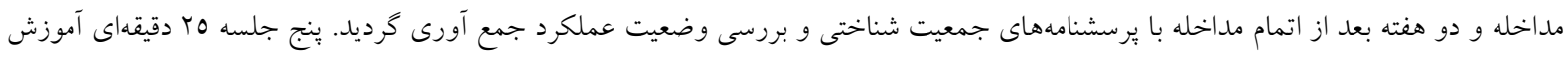

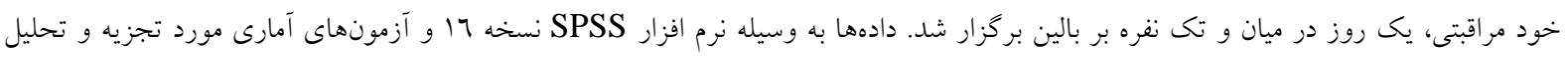

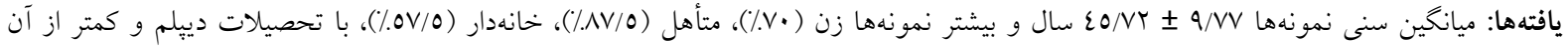

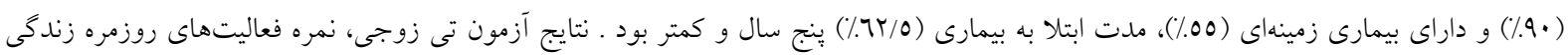

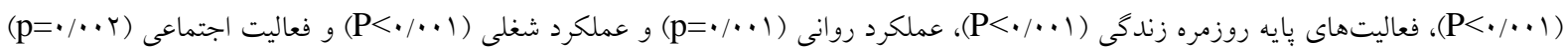

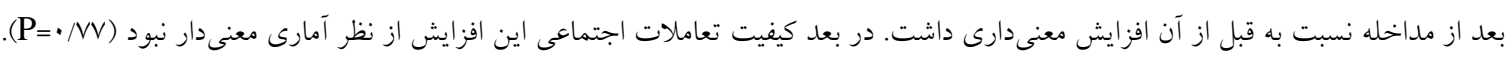

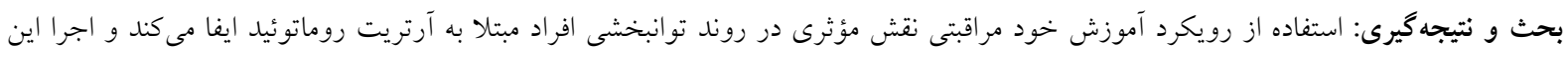

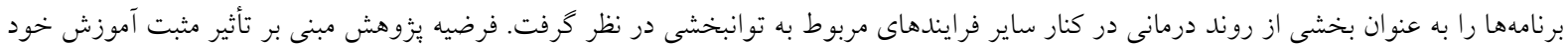

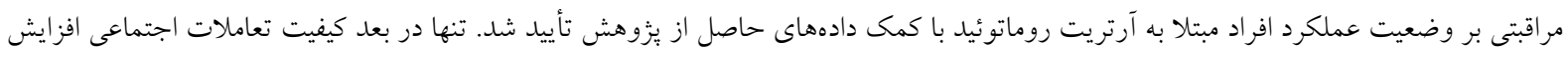

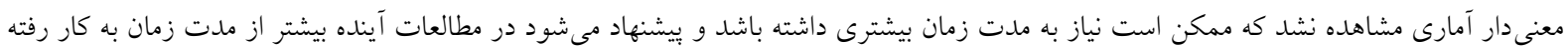
در اين مطالعه براى بررسى تغييرات صرف شود.

كليد وازهها: آرتريت روماتوئيد، آموزش به بيمار، خود مراقبتى، فعاليت روزمره زندىى.

$$
\begin{aligned}
& \text { تعارض منافع: ندارد }
\end{aligned}
$$

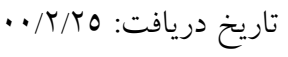

$$
\begin{aligned}
& \text { تاريخ يذيرش: ب/0/ro }
\end{aligned}
$$

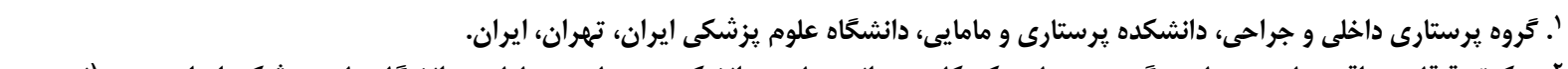

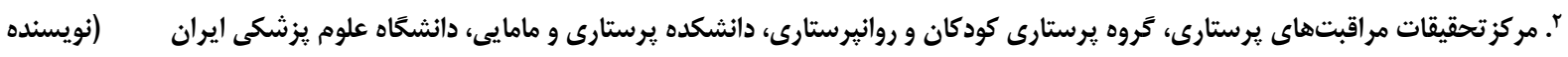

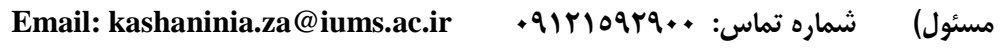

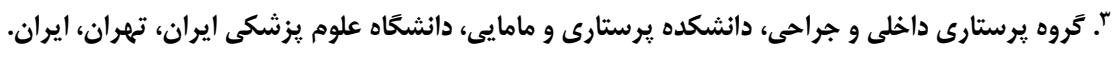

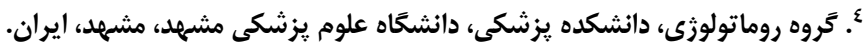

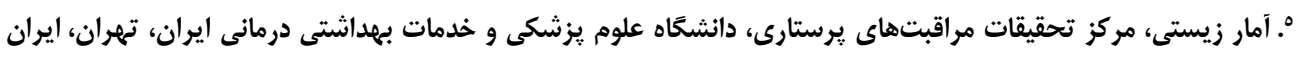


افراد صورت كيرد("ا). از اينرو مفهومى به نام خود مر اقبتى مطرح شده است.

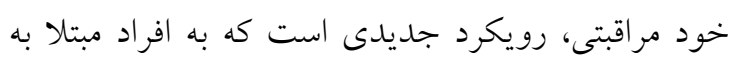
بيمارىهاى مزمن كمك مى كند راحت تر با بيمارى خود

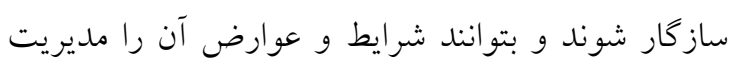

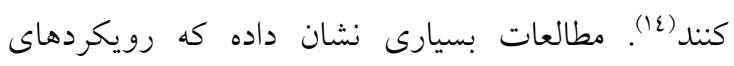

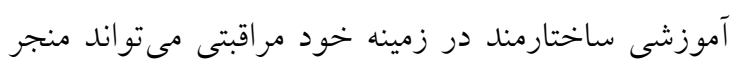
به بهبود وضعيت عملكرد و سلامت بيماران مبتلا به بيمارى

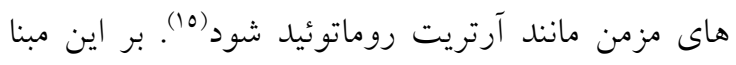
بيماران بايد دانش و مهارتهاى مورد نياز براى تصميم كيرى و حل مشكلات خود و مشكلات ارتباطى با ديخران را كسب كنند (17). آموزش خود مراقبتى در اين بيماران كمك مى كند به سطحى از سلامت برسند كه در آن نه تنها داراى يك زندكى شخصى رضايت بخش باشند، بلكه بتو انند همكارى

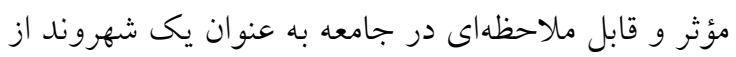

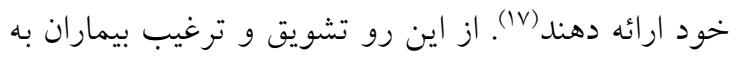
اتخاذ رفتارهاى مناسب و صحيح مراقبت از خود، عاملى دهن

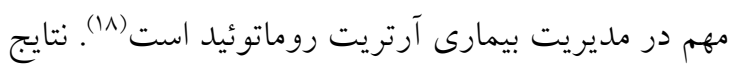

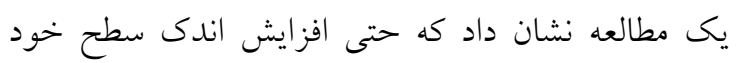

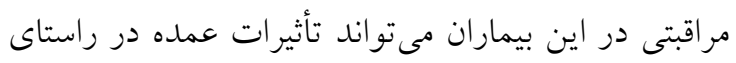

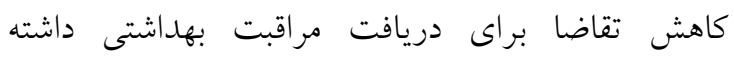

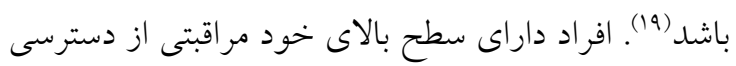

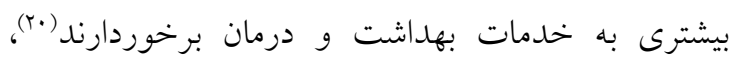

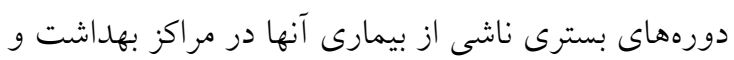

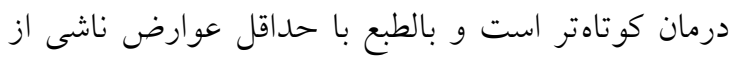
بسترى در اين مراكز رو به رو مى شوند (II) و مشاركتى فعال در تصميم گيرى و روند بهبود و ارتقاى سلامت و همجنين

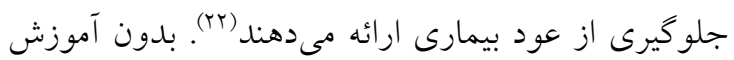

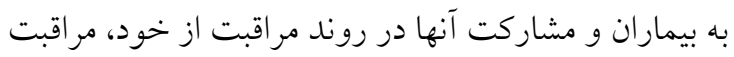
هاى بهداشتى هزينه بيشترى خواهد داشت و كيفيت

$$
\text { زندكى كاهش مى يابد (Tr) }
$$

آموزش بيماران مىتواند دانش آنها را افزايش داده و منجر يابر به بهبود فعاليتهاى خود مراقبتى و ارتقاء وضعيت

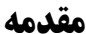
آرتريت روماتوئيد (Rheumatoid Arthritis) از جمله

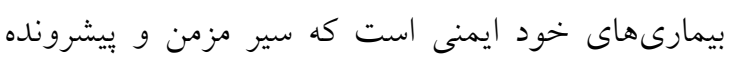

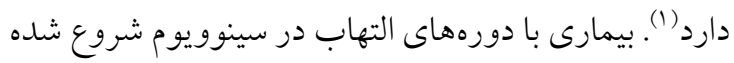
و موجب ضخيم شدن آن و بروز ادم در بافت سينوويال

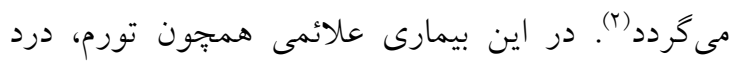
پايدار، حساس شدگى، سفتى و خشكى مفاصل، تخريب

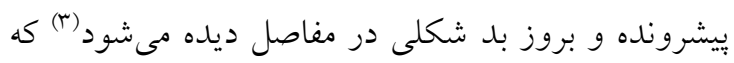

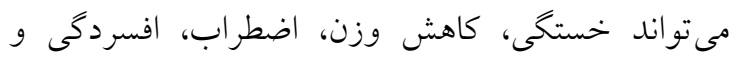

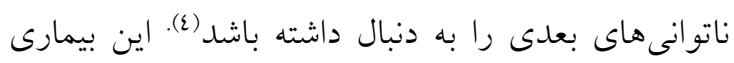

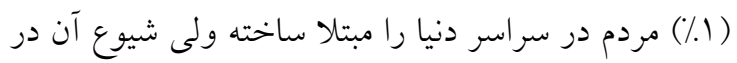
مناطق مختلف، در نزادهاى گوناگون و گروههاى مختلف

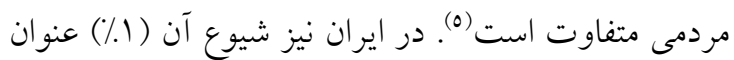

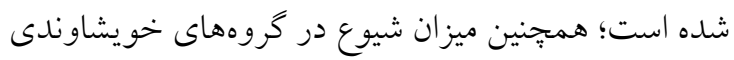

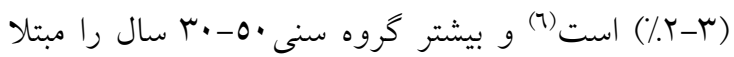

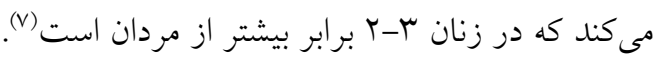

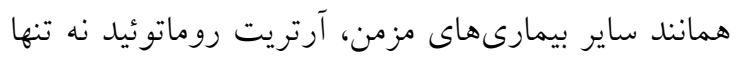

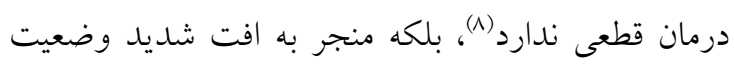

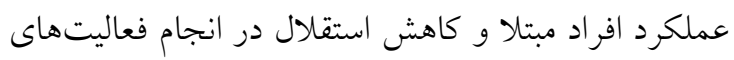

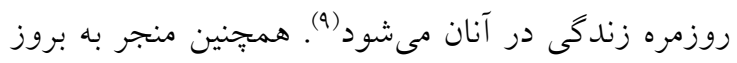

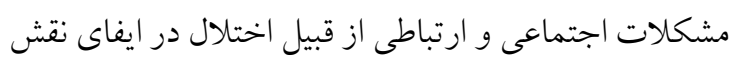

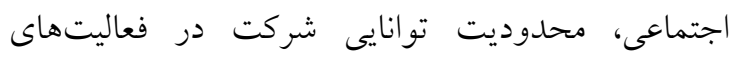
اجتماعى، بروز مشكلات جنسى و عاطفى و بروز برون

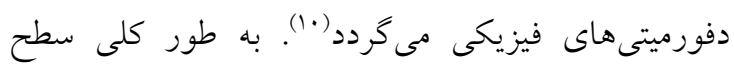
وضعيت عملكرد و فعاليتهاى روزمره زندكى افراد مبتلا فئل

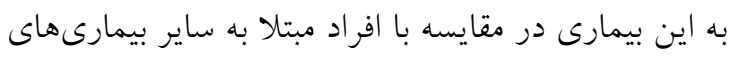

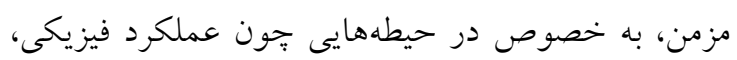
نقش فردى و شغل، درد و عملكرد اجتماعى يايين تر

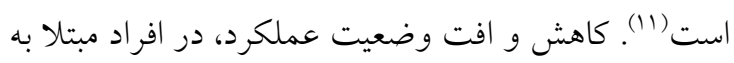

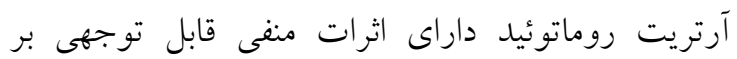
خانو اده بيماران، ارائه دهندكان مر اقبتهاى بهداشتى و نيز جامعه مىباشد(r)". با توجه به اينكه ماهيت اين بيمارى مزمن است و بيمارىهاى مزمن، نيازمند مراقبت مداوم هستند، بسيارى معتقدند اين مراقبتها بايد توسط خود 
هدف تعيين اثربخشى آموزش خود مراقبتى بر وضعيت

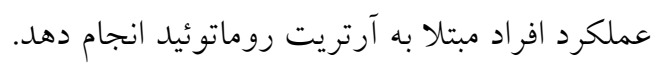

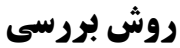

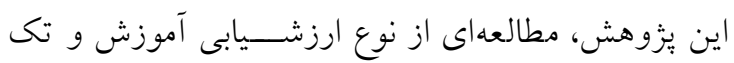

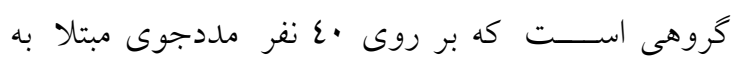

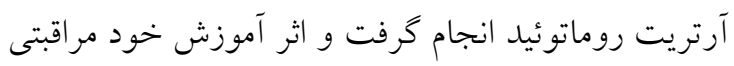

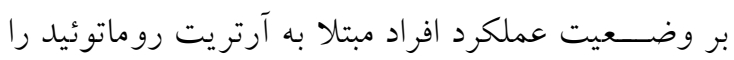
مورد ارز يابى قرار داد. براى تعيين حجم نمو نه لازم در برد

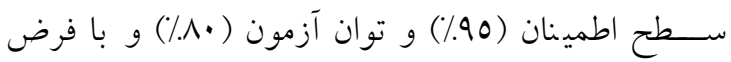

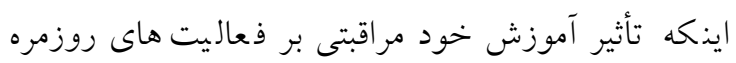

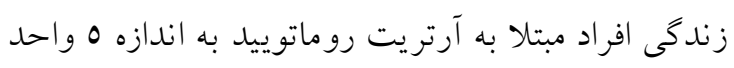

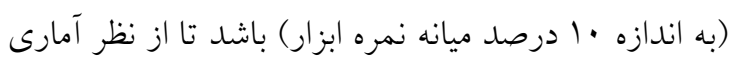

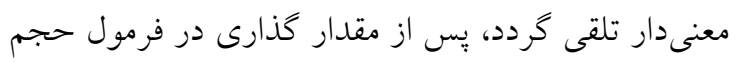

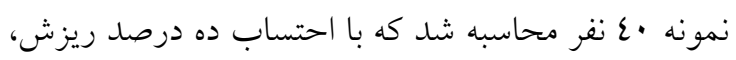

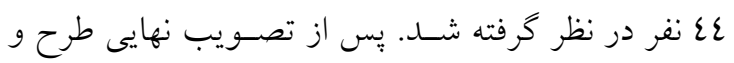
اخذ كد اخلاق به شنا سه

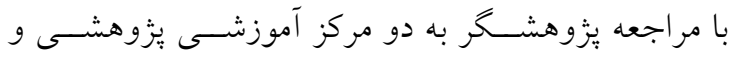

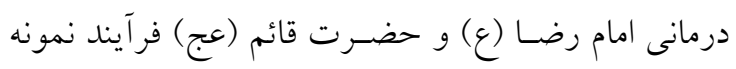

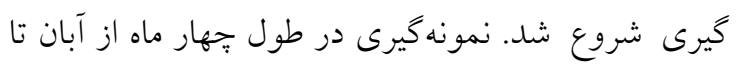

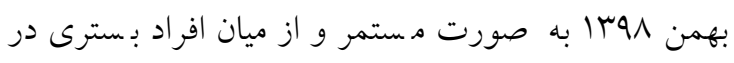

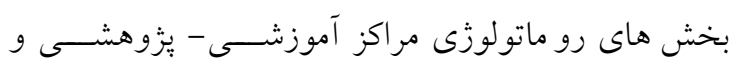

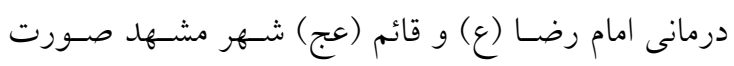

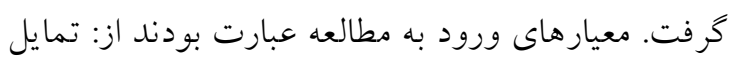

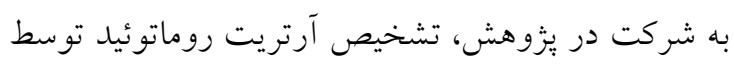

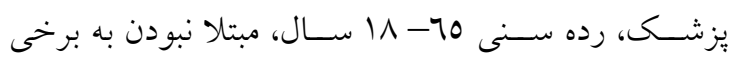

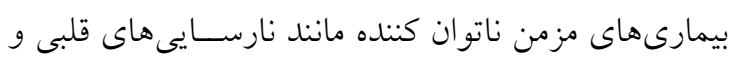

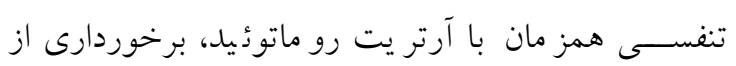

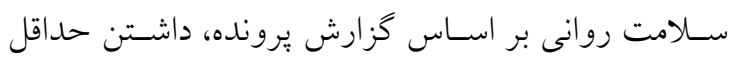

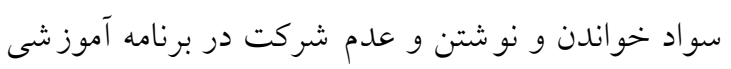
مربوط به بيمارى آرتريت روماتوئيد.

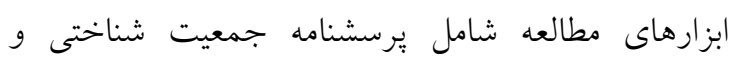

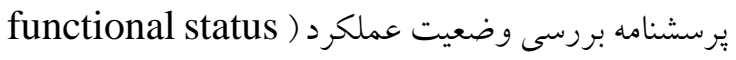
(questionnaire
سلامت شود(ع)، جنانكه بيماران مىتوانند خود را براى تصميم كيرى و مطابقت با رزيم درمانى آماده كنند. شايان ذكر است كه هدف اصلى آموزش خود مراقبتى، تغيير رفتار

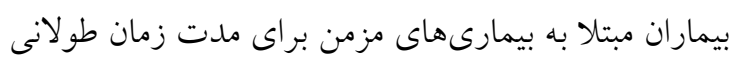

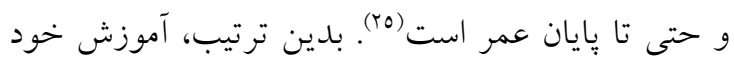

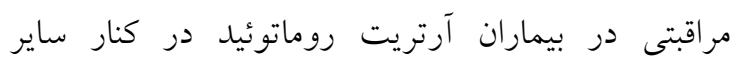

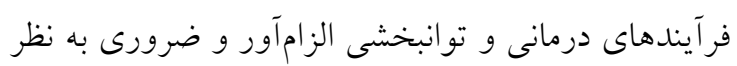

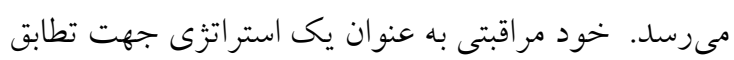

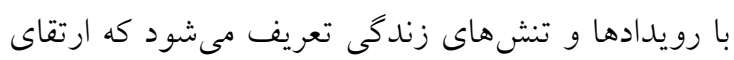
وضعيت عملكرد و فقدان وابستخى افراد را در يى دارد (ب7).

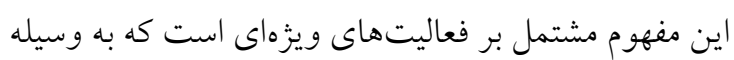

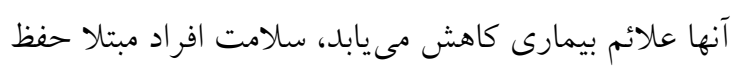

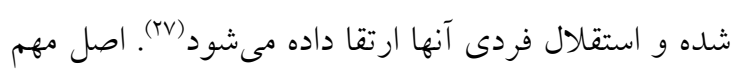

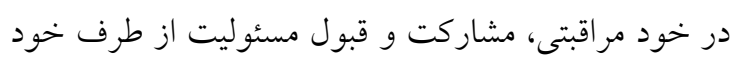

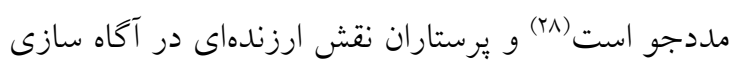
و آموزش بيمار ان دارند و اين جزء مهمى از وظايف مستقل

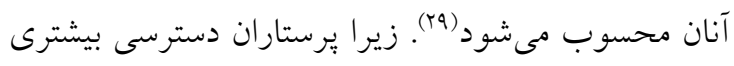

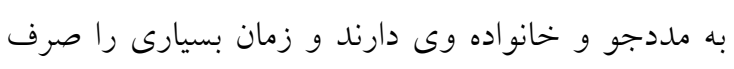

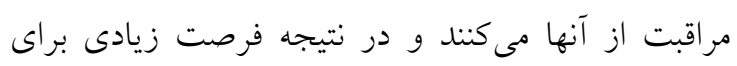

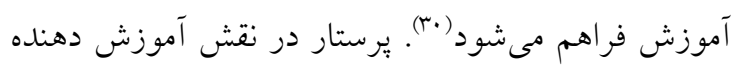

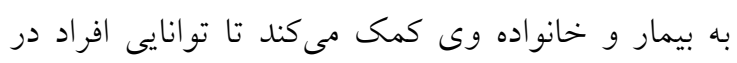
مراقبت از خود افزايش يابد و در نتيجه سلامتى ارتقاء يافته ونه

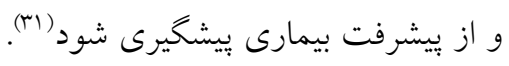

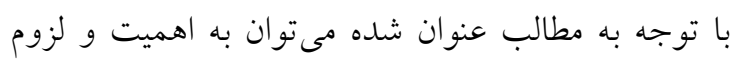

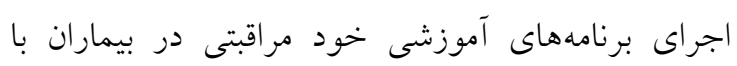

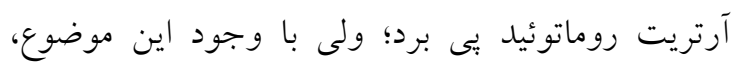

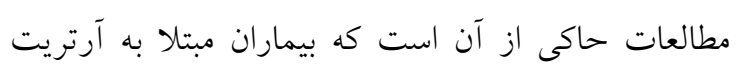

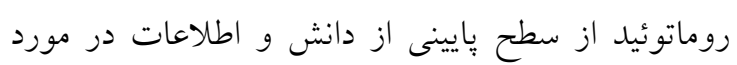

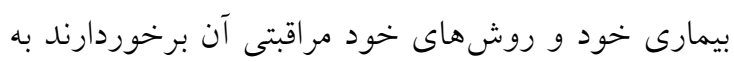
كونهاى كه كمبود دانش منجر به عود مكرر بيمارى و بالا

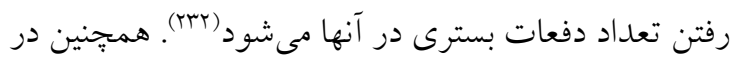

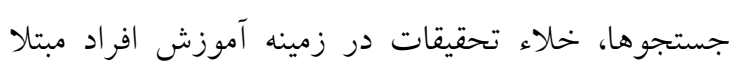

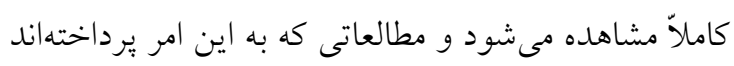

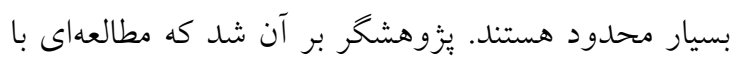


خوب را نشان مىدهد. جهت تعيين روايى ابزار، يرسشنامه وضعيت عملكرد به همراه ترجمه فارسى آن در اختيار

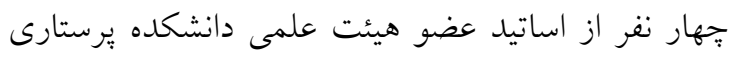

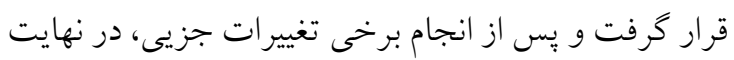

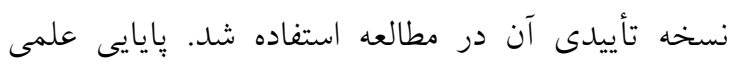

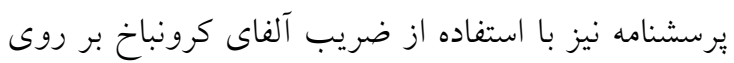
دادههاى مربوط به •r نفر از بيماران محاسبه كرديد كه در مطالعه وارد نشدند. اين مقدار در حيطه فعاليتهاى روزمره

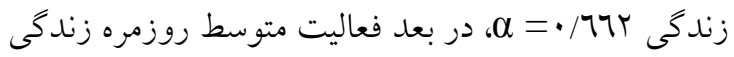

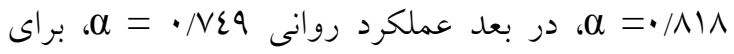

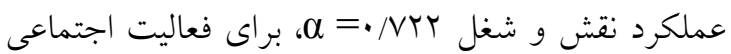

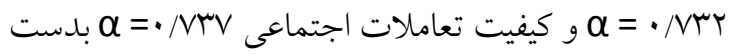
آمد. يرسشنامه جمعيت شناختى نيز سن، جنسيت، وضعيت

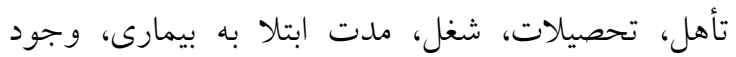

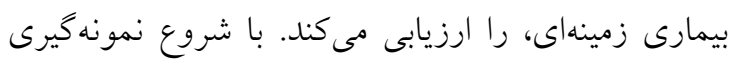

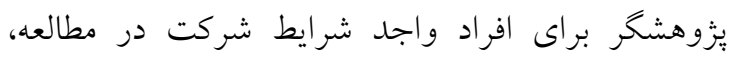

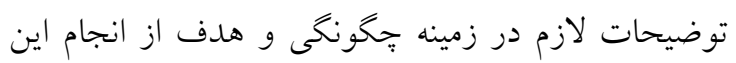

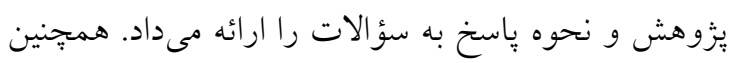

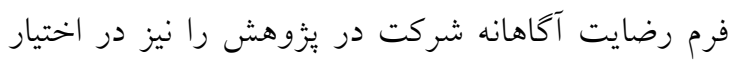

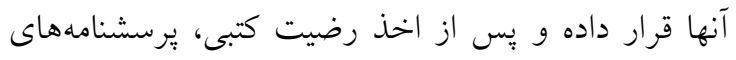
جمعيت شناختى و بررسى وضعيت عملكرد نيز در اختيار

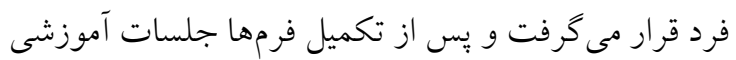
شروع شد. يُزوهشكر مسئول بركزارى جلسات و و ارائه

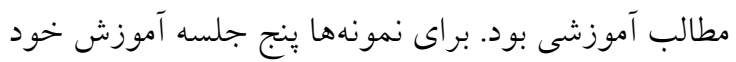

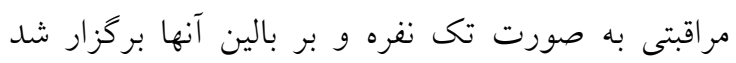

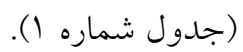

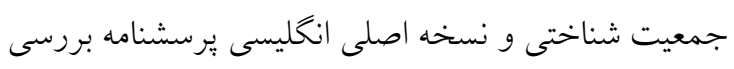

عملكرد داراى Y Tؤ ال است كه عملكرد افراد را در شش بعد شامل فعاليت روزمره زندكى (r سؤال در طيف ليكرت

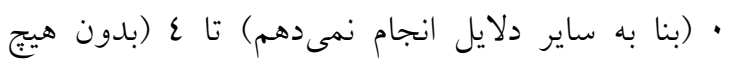

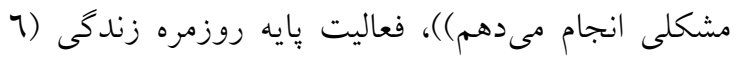

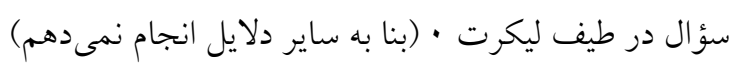

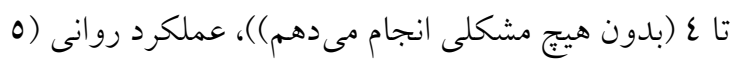

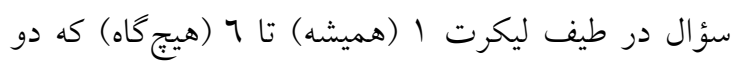
سؤال داراى نمره معكوس بود)، عملكرد شغلى (7 سؤال در طيف ليكرت ا (هميشه) تا ع (هيج كاه) كه دو سؤال نيز

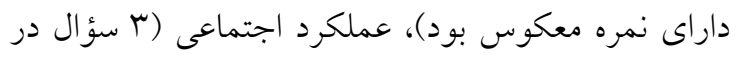

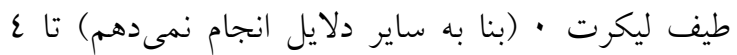
(بدون هيج مشكلى انجام مىدهم)) و كيفيت تعاملات

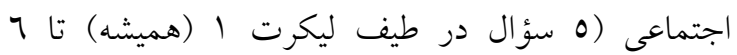
(هيج گاه) كه نمره دهى دو سؤال نيز معكوس بود) مورد

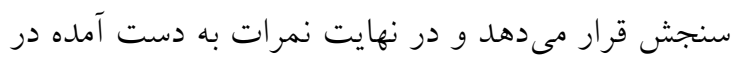

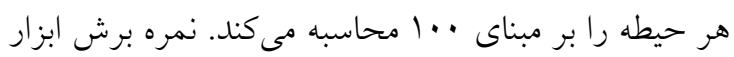

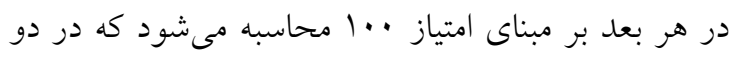

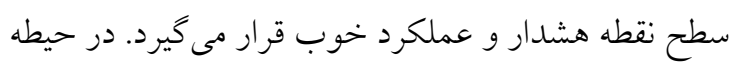
فعاليتهاى روزمره زندگى نمرات

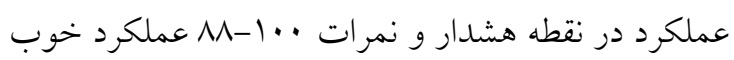

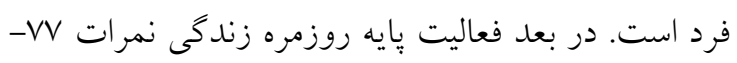

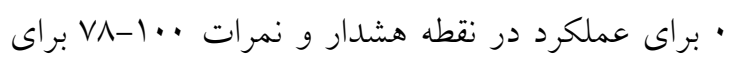

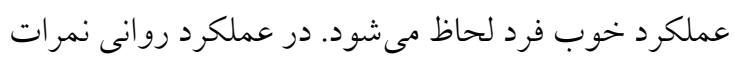

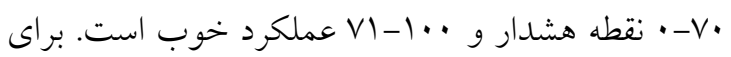

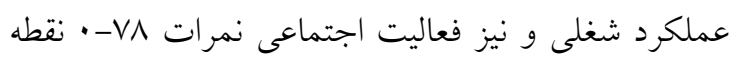

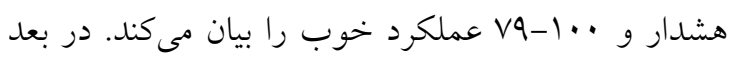
كيفيت تعاملات اجتماعى بازه نمرات 79-• نشان دهنده

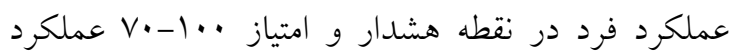
جدول شماره ا: محتواى جلسات آموزش خود مراقبتى در بيمارى آرتريت روماتوئيد

\begin{tabular}{|c|c|c|}
\hline 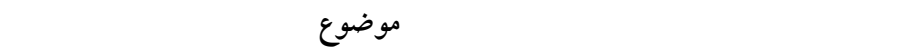 & مدت زمان & 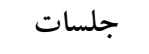 \\
\hline شناخت بيمارى، عوارض، داروها و درمانها & 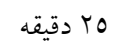 & جلسه اول \\
\hline خود مراقبتى در حيطه جسمى، فعاليتهاى بلدنى و ورزشى. & 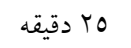 & 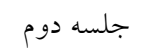 \\
\hline خود مراقبتى در حيطه عملكرد روانى روشهاى مديريت استرس، بهبود سلامت روانى. & 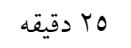 & جلسه سوم \\
\hline روشهاى ارتقاء سلامت، بهبود عملكرد اجتماعى و شغلى. & 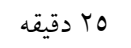 & جلسه جهارم \\
\hline خود مراقبتى در انجام فعاليتهاى روزمره زندگى. & To roقه & جلسه ينجم \\
\hline
\end{tabular}


جدول شماره r: توزيع فراوانى ميانكين و انحراف معيار

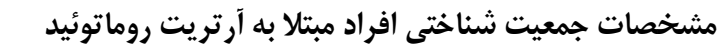

\begin{tabular}{|c|c|c|c|}
\hline درصد & فراوانى & ات جمعيت شناختى & مشخع \\
\hline$r \cdot$ & ir & كمتر از •ع & \\
\hline ro & $1 \varepsilon$ & $\varepsilon \cdot-\varepsilon q$ & سن (سال) \\
\hline ro & $1 \varepsilon$ & ل مو بيشتر & \\
\hline $1 \ldots$ & $\varepsilon$. & جمع كل & \\
\hline \multicolumn{2}{|c|}{$\varepsilon 0 / 9 \pm 9 / V V$} & انحراف معيار 土 ميانخين & \\
\hline \multicolumn{2}{|c|}{$r \cdot-7 \varepsilon$} & بيشينه - كمينه & \\
\hline$r \cdot$ & IT & مرد & \\
\hline v. & rᄉ & 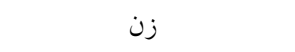 & جنسيت \\
\hline $1 \ldots$ & $\varepsilon$. & جمع كل & \\
\hline$\Lambda V / 0$ & ro & متأهل & \\
\hline 1. & $\varepsilon$ & مجرد & وضعيت \\
\hline$r / 0$ & 1 & 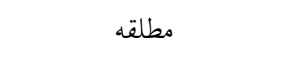 & تأهل \\
\hline $1 .$. & $\varepsilon$. & جمع كل & \\
\hline 0. & $r$. & كمتر از دييلم & \\
\hline$\varepsilon \cdot$ & 17 & دييلم & تحصيلات \\
\hline 1. & $\varepsilon$ & تحصيلات دانشخاهى & \\
\hline $1 .$. & $\varepsilon$. & جمع كل & \\
\hline ro & 1. & آزاد & \\
\hline $\mid r / 0$ & 0 & 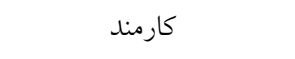 & \\
\hline$r / 0$ & 1 & دانشجو & | ( ) مغل \\
\hline$r / 0$ & 1 & بيكار & \\
\hline$O V / O$ & r & خانهدار & \\
\hline 1. & $\varepsilon$. & جمع كل & \\
\hline 10 & 7 & كمتر از يك & مدت ابتلا \\
\hline$r T / O$ & 9 & يك تا دو & به بيمارى \\
\hline ro & 1. & سه تا بنج & (سال) \\
\hline$r v / 0$ & 10 & بيشتر از ينج & \\
\hline 1. & $\varepsilon$. & جمع كل & \\
\hline 00 & rr & بلى & بيمارى \\
\hline ¿o & 11 & خير & زمينهاى \\
\hline $1 .$. & $\varepsilon$. & جمع كل & \\
\hline
\end{tabular}

نتايج آزمون تى زوجى در جدول شماره ب حاكى از آن بود

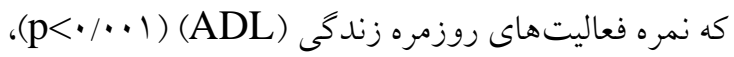

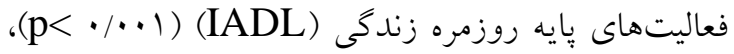

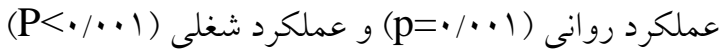

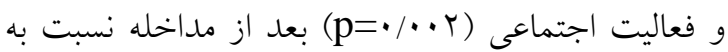

در پايان آخرين جلســه نيز كتابحه آموزشــى در زمينه

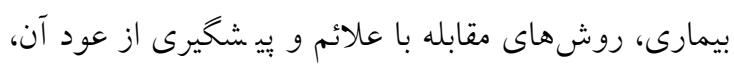

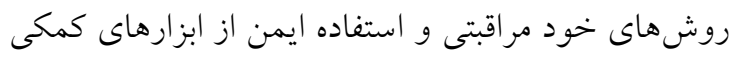

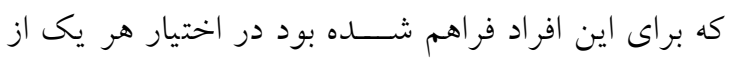

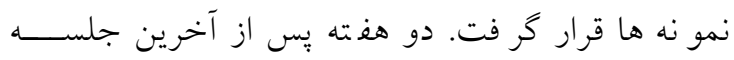

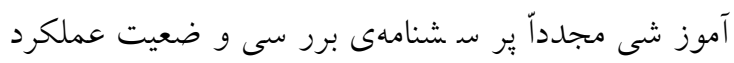

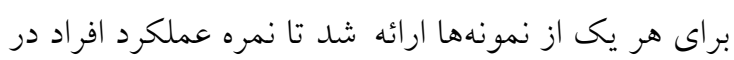
حيطههاى مختلف بعد از مداخله ثبت شود. بِ إز تكميل

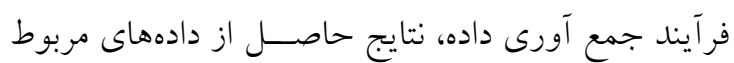

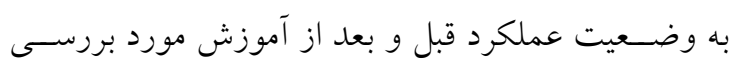
قرار كر فت. تجز يه و تحليل داده ها در دو بخش آ مار

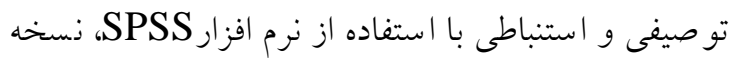
17 انجام شد. در بخش آمار تو صيفى از فراوانى و در صد بد بـ براى متغيرهاى كيفى، و شاخصهاى علدى دلى كمينه، بيشينه

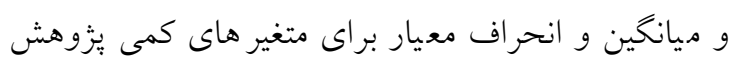

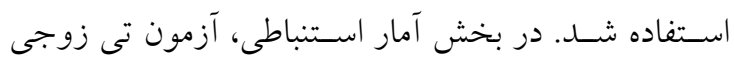
براى مقايسه قبل و بعد از مداخله استفاده شد.

\section{يافتهها}

در مجموع rع نفر به عنوان نمونه انتخاب شدند كه شامل

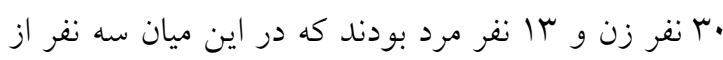

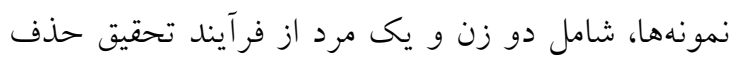

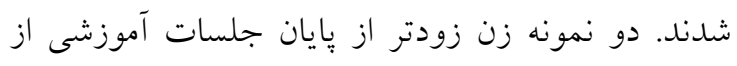
بخش مرخص شدند و به جلسات باز نخشتند و نمونه مرد

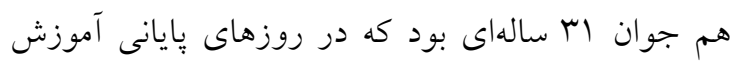

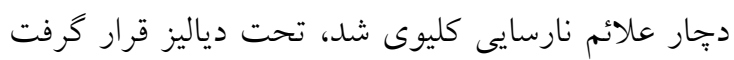
و بدين ترتيب از مطالعه كنار كذاشته شد. بدين ترتيب تئري مطالعه با •ع نفر نمونه به بايان رسيد. تونه

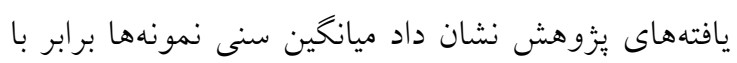

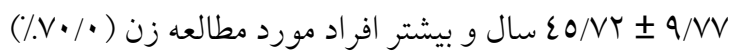

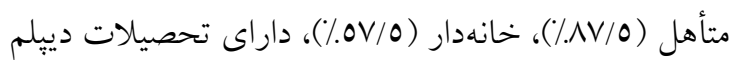

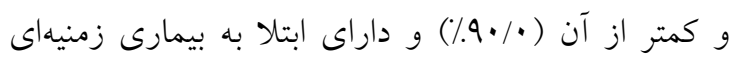
(00\%) بودند. مدت ابتلا به آرتريت روماتوئيد در بيشتر

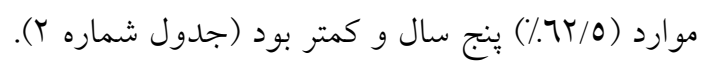


نشان دادند. در بعد عملكرد نقش و شغل نيز قبل مداخله ميانخين نمره براى همه افراد در نقطه هشدار قرار داشت اما بعد از انجام مداخله ( • • (\%) نمونهها عملكرد خوبى داشتند. در بعد فعاليت اجتماعى قبل انجام مداخله ( •/90/) افراد مورد بررسى در نقطه هشدار قرار داشتند بعد از مداخله (•/VO/) افراد نمونه در نقطه هشدار و (•/YO/\%) عملكرد خوبى نشان دادند. در بعد كيفيت تعاملات اجتماعى قبل مداخله (•/^0/٪) افراد مورد بررسى در نقطه

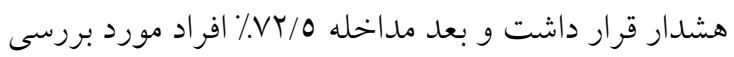
در نقطه هشدار بودند و (rV/O/.) عملكرد خوبى نشان

دادند.
قبل از آن افزايش معنى دارى داشته است. اما در بعد كيفيت تعاملات اجتماعى اين افزايش از نظر آمارى معنىدار نبود همجينين در رابطه با نقطه برش ابزار، يافتهها در جدول شماره ب نشان داد نمره فعاليتهاى روزمره زندگى قبل مداخله براى همه نمونهها در نقطه هشدار قرار داشت ولى بعد مداخله ( •/01\%)عملكرد خوب نشان دادند. در بعد فعاليتهاى متوسط روزمره زندكى نيز براى همه افراد مورد بررسى ميانگين نمره قبل مداخله در نقطه هشدار

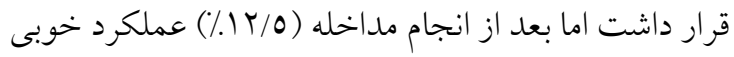
داشتند. در بعد عملكرد روانى قبل مداخله (•/ •^./) افراد مورد بررسى در نقطه هشدار قرار داشتند اما بعد از انجام مداخله (•/Vo/\%) در نقطه هشدار و (•/\%0/\%) عملكرد خوب

جدول شماره سا: توزيع فراوانى و شاخصهاى عددى وضعيت عملكرد و ابعاد آن در افراد مبتلا به آرتريت روماتوئيد قبل و بعد از اجراى

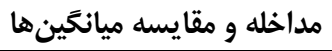

\begin{tabular}{|c|c|c|c|c|c|c|}
\hline \multirow{2}{*}{ نتيجه آزمون تى زوجى } & \multicolumn{2}{|c|}{ بعد } & \multicolumn{2}{|c|}{ قبل } & \multicolumn{2}{|c|}{ 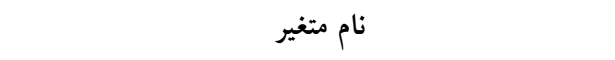 } \\
\hline & درصد & فراوانى & درصد & فراوانى & & \\
\hline$t=r / v i r$ df $=r q$ & 10 & $r \varepsilon$ & $1 \cdots$ & $\varepsilon$. & نقطه هشدار (AV-•) & \\
\hline $\mathrm{p}<\cdot / \cdots 1$ & 10 & 7 & . & . & عملكرد خوب ( (1)-1) & فعاليت روزمره زندگى \\
\hline & $1 \ldots$ & $\varepsilon$. & $1 \cdots$ & $\varepsilon$. & جمع كل & $(1 \cdot \cdot-\cdot)$ \\
\hline$t=r / v i r$ df $=r q$ & \multicolumn{2}{|c|}{$V T / 0 \pm 1 \% / 1}$. & \multicolumn{2}{|c|}{$7 / / T 0 \pm 1 \cdot / 2 r$} & انحراف معيار 土 ميانخين & \\
\hline $\mathbf{p}<\cdots \cdot \cdots 1$ & \multicolumn{2}{|c|}{$1 \cdots-0}$. & \multicolumn{2}{|c|}{$\Lambda r-\varepsilon r$} & بيشينه - كمينه & \\
\hline $\mathrm{t}=\wedge / \Delta \vee q \mathrm{df}=r q$ & $\Lambda \mathrm{V} / 0$ & ro & $1 \cdots$ & $\varepsilon$. & نقطه هشدار (VV-••) & \\
\hline $\mathrm{p}<\cdot / \cdots 1$ & $1 T / 0$ & 0 & · & · & 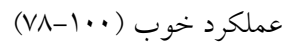 & فعاليت حد متوسط روزمره \\
\hline $\mathrm{t}=\Lambda / 0 \vee q \mathrm{df}=r q$ & \multicolumn{2}{|c|}{$09 / 17 \pm 10 / 01$} & \multicolumn{2}{|c|}{$r q / 19 \pm 1 / 17$} & انحراف معيار 土 ميانخين & زندگى (•-1-•) \\
\hline $\mathrm{p}<\bullet / \cdots 1$ & \multicolumn{2}{|c|}{$Q T-Y q$} & \multicolumn{2}{|c|}{$7-r q$} & بيشينه - كمينه & \\
\hline$t=r / v 7 r$ df $=r q$ & vo & $r$. & $\wedge$. & rt & نقطه هشدار (•V-••) & \\
\hline \multirow[t]{2}{*}{$\mathrm{p}=\cdot / \cdots 1$} & ro & 1. & r. & $\wedge$ & عملكرد خوب ( ( VI-1) & عملكرد روانى (·-·.") \\
\hline & $1 \cdots$ & $\varepsilon$. & $1 \cdots$ & $\varepsilon$. & جمع كل & \\
\hline$t=r / v 7 r$ df $=r q$ & \multicolumn{2}{|c|}{$\Delta \nabla / 1 \cdot \pm 1 \varepsilon / r}$. & \multicolumn{2}{|c|}{$29 / 5 \cdot \pm 17 / 99$} & انحراف معيار 土 ميانخين & \\
\hline $\mathrm{p}=\cdot / \cdots 1$ & \multicolumn{2}{|c|}{$\wedge \varepsilon-r \varepsilon$} & \multicolumn{2}{|c|}{$1 \cdot-17$} & بيشينه - كمينه & \\
\hline$t=\varepsilon / r q 0$ df $=r q$ & 9. & ry & $1 \cdots$ & $\varepsilon$. & نقطه هشدار (VN-••) & \\
\hline \multirow[t]{2}{*}{$\mathrm{p}<\cdot / \cdot \cdot 1$} & 1. & $\varepsilon$ & . & . & 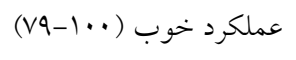 & عملكرد نقش و شغل \\
\hline & $1 \cdots$ & $\varepsilon$. & $1 \cdots$ & $\varepsilon$. & جمع كل & $(\cdot-1 \cdot \cdot)$ \\
\hline$t=\varepsilon / r q 0 \mathrm{df}=r q$ & \multicolumn{2}{|c|}{$\varepsilon q / \varepsilon \varepsilon \pm r Y / \cdot V$} & \multicolumn{2}{|c|}{$r \Lambda / \varepsilon V \pm I N / r$} & انحراف معيار 土 ميانخين & \\
\hline $\mathrm{p}<\cdot / \cdots 1$ & \multicolumn{2}{|c|}{$\wedge \varepsilon-\cdot$} & \multicolumn{2}{|c|}{$v_{r-} \cdot$} & بيشينه - كمينه & \\
\hline $\mathrm{t}=r / r \varepsilon \wedge \mathrm{df}=r q$ & 90 & r & vo & $r$. & نقطه هشدار (VN-•) & \\
\hline$p=\cdot \cdots r$ & $\circ$ & r & ro & 1. & عملكرد خوب (1)-Vq) & فعاليت اجتماعى \\
\hline
\end{tabular}




\begin{tabular}{|c|c|c|c|c|c|c|}
\hline & $1 \cdots$ & $\varepsilon$ & $1 \cdots$ & $\varepsilon$ & جمع كل & \multirow[t]{3}{*}{$(\cdot-1 \cdot \cdot)$} \\
\hline $\mathrm{t}=r / r \varepsilon \wedge$ df $=r q$ & \multicolumn{2}{|c|}{$70 / \cdots \pm 1 N / \cdot r$} & \multicolumn{2}{|c|}{$00 / \cdots \pm|\varepsilon / V|$} & انحراف معيار 土 ميانخين & \\
\hline$p=\cdot / \cdots r$ & \multicolumn{2}{|c|}{$9 Y-r r$} & \multicolumn{2}{|c|}{$\Lambda \varepsilon-\mu$} & بيشينه - كمينه & \\
\hline$t=1 / \wedge 1 \wedge d f=r q$ & $V Y / O$ & rq & 10 & $r \varepsilon$ & نقطه هشدار (79-•) & \multirow{5}{*}{ كيفيت تعاملات اجتماعى } \\
\hline \multirow[t]{2}{*}{$\mathrm{p}=\cdot / \mathrm{VV}$} & $r V / 0$ & 11 & 10 & 7 & 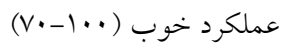 & \\
\hline & $1 \cdots$ & $\varepsilon$. & $1 \cdots$ & $\varepsilon$ & جمع كل & \\
\hline$t=1 / \wedge) \wedge d f=r q$ & \multicolumn{2}{|c|}{$7 \cdot \pi \cdot \pm 10 / 07$} & \multicolumn{2}{|c|}{$07 / \mu \cdot \pm 10 / \cdots$} & انحراف معيار 土 ميانخين & \\
\hline $\mathrm{p}=\cdot / \mathrm{VV}$ & \multicolumn{2}{|c|}{$\cdots-r \Lambda$} & \multicolumn{2}{|c|}{$\cdots-r \Lambda$} & بيشينه - كمينه & \\
\hline
\end{tabular}

آموزشى بهبود معنى دارى بيدا كرد بطوريكه نتايج نشان

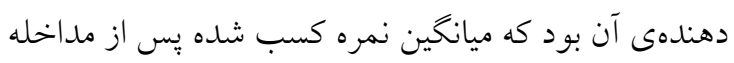

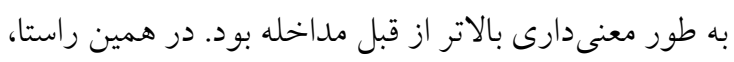
در يزوهشى كه توسط حبيبزاده و همكاران در دانشخاه

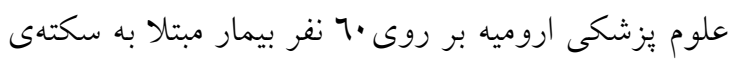
مغزى با آموزش برنامهى خود مراقبتى انجام شد، يافتهها

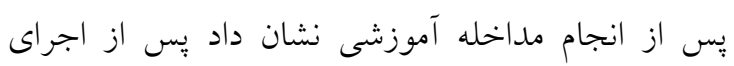

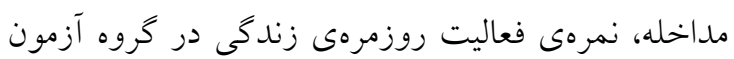

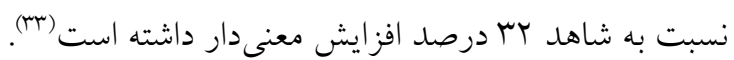
در مطالعه مسعودى و همكاران نيز كه بر روى بيماران مبتلا به مولتييل اسكلروزيس در انجمن ام اس ايران صورت

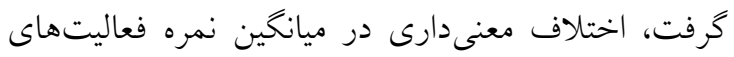
روزمره زندكى قبل مداخله آموزشى مشاهده نشد. در

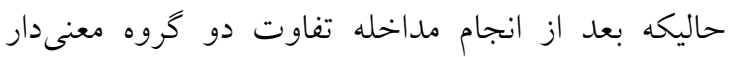

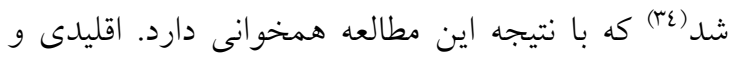

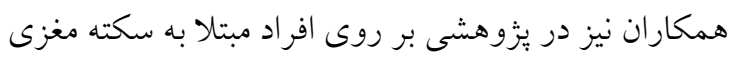

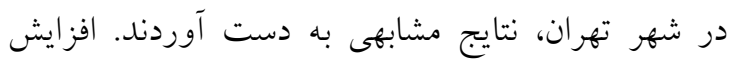

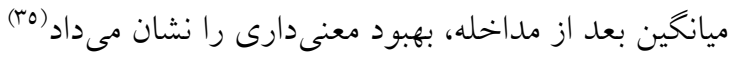
كه با نتايج به دست آمده در مطالعه حاضر همخوانى دارد. بها.

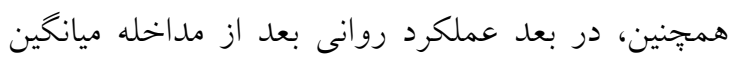

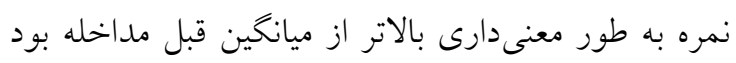

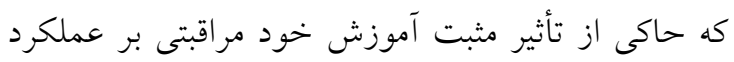

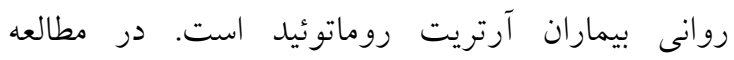
arvidson

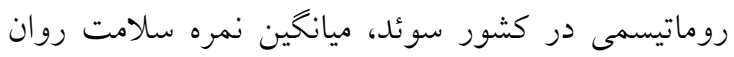

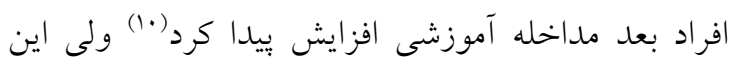

\section{بحث و نتيجه تيرى}

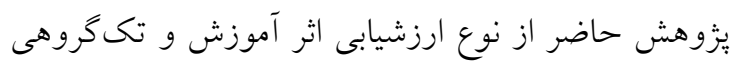

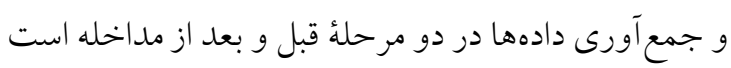
كه بر روى ·ع نفر از بيماران مبتلا به آرتريت روماتوئيد

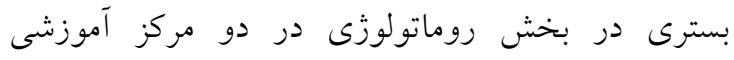

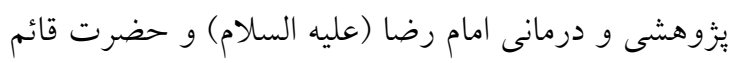
(عج) در شهر مشهد انجام شده است.

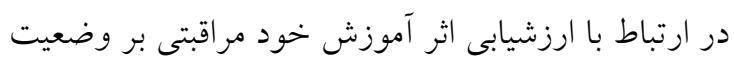

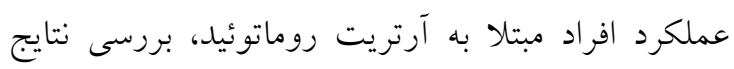
نشان مىدهد وضعيت عملكردى در همهى ابعاد به غير از

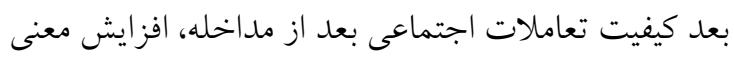

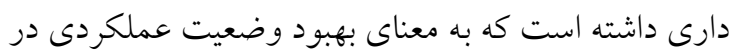
واحدهاى مورد يزوهش است. نتايج مشابه مطالعه

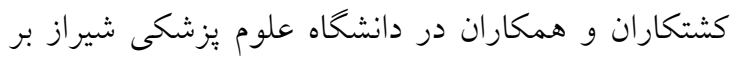

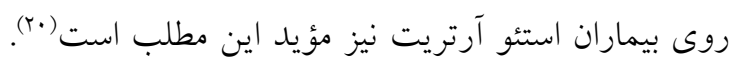

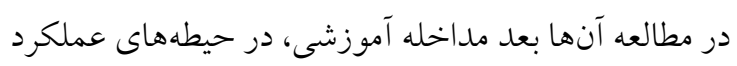
جسمى، عملكرد اجتماعى، سلامت روانى عمومى، درد،

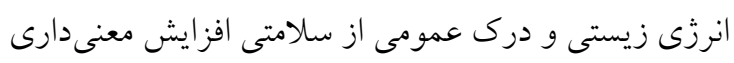

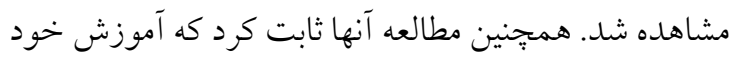

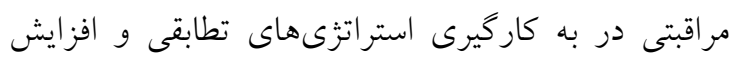

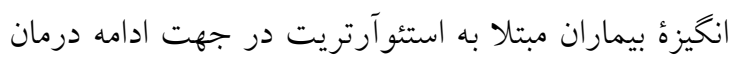

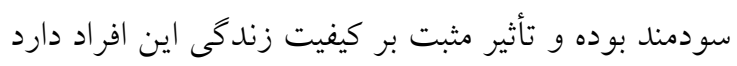

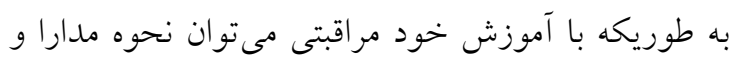
تطابق با بيمارى را به نحو مؤثرترى فراهم كرد (•r.).

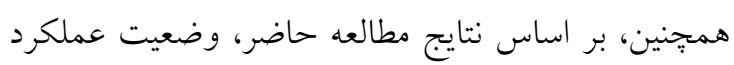

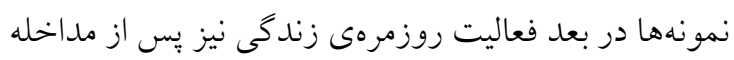


آرتريت روماتوئيد برداختند و نشان دادند به كارگيرى اين

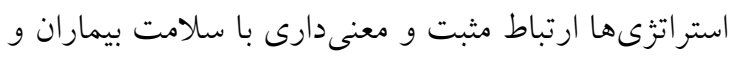

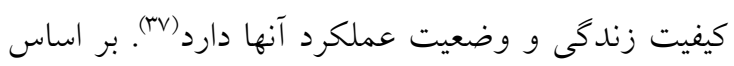

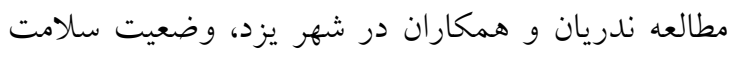

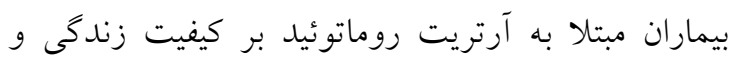

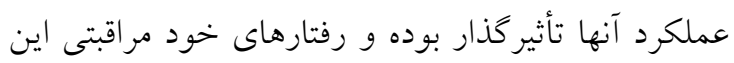
بيماران بيشبينى كننده و ارتقاء دهنده سلامت و وضعيت

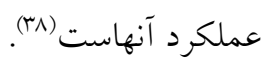
نتايج مطالعه حاضر نشان داد كه مداخله آموزشى بر كيفيت

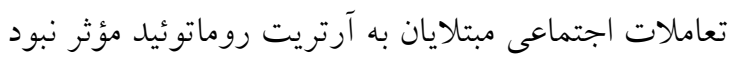
كه ممكن است نياز به مداخله با مدت زمان بيشترى باشد

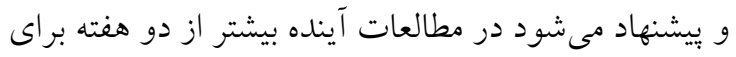

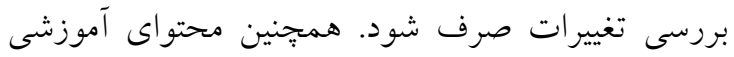

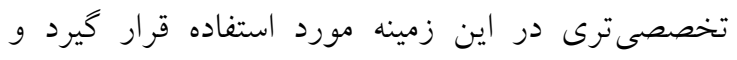

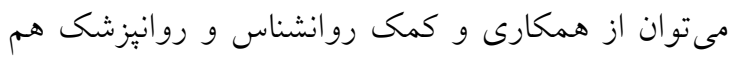

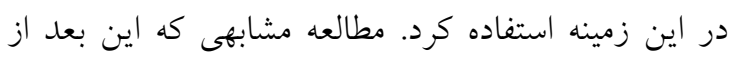
وضعيت عملكرد را مورد بررسى قرار داده باشد يافت نشد.

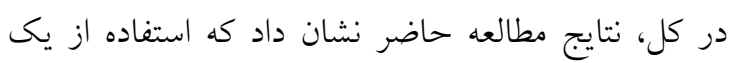

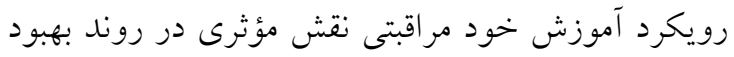

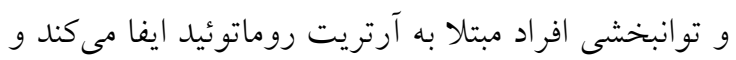

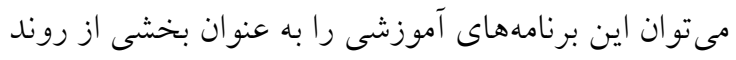

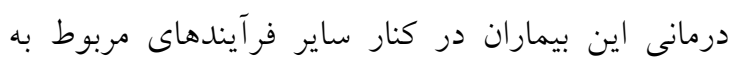

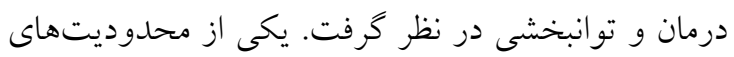

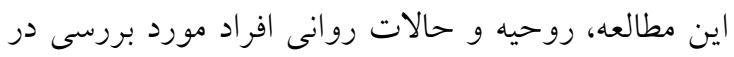

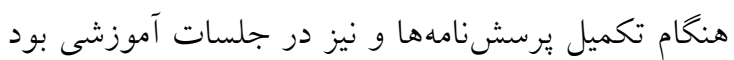

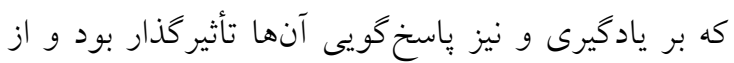

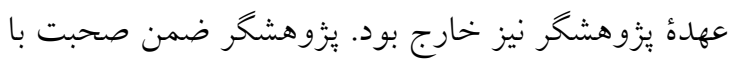
مددجو و انتخاب زمان مناسب براى تكميل يرسشنامهها و آموزش را هماهنگ مى منمود. همجنين دسترسى نداشتن به مددجويان جهت كتترل آنها در نحوهى آنهام انهام

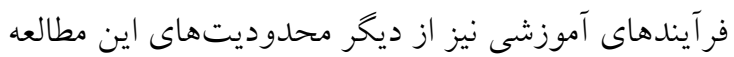

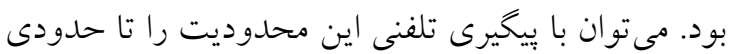

$$
\text { برطرف كرد. }
$$

افزايش از نظر آمارى معنى دار نبود كه ممكن است به اين

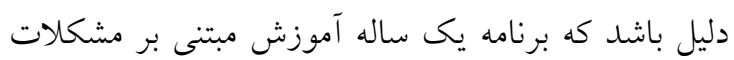

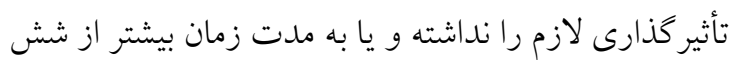
ماه براى بهبود معنى دار نياز بوده است.

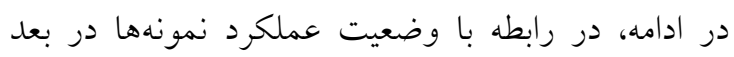
عملكرد نقش و شغل نيز ارزيابى نتايج نشان داد كه ميانخين نمرهى كسب شده بعد از مداخله بهطور معنىدارى بالاتر

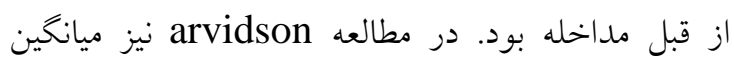
نمرهى عملكرد نقش و شغل افراد مبتلا به بيمارىهاى

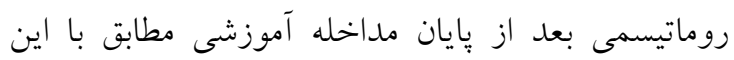

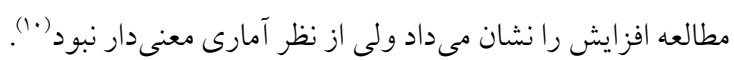
اين مطالعه نشان داد كه فعاليت اجتماعى افراد مبتلا به داديه ناتوانى حاصل از بيمارى آرتريت روماتوئيد را به لهن عنوان

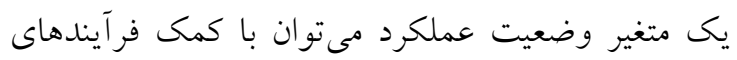

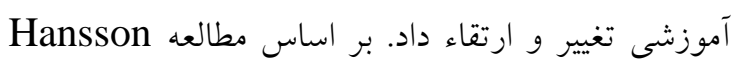

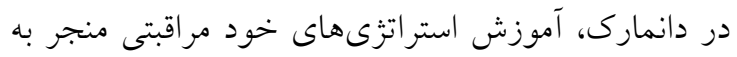
بهبود كيفيت زندگى و عملكرد بيماران آرتريت روماتوئيد كرديد كه بيانكر اين مطلب است كه انجام رفتارهاى خودود مراقبتى باعث افزايش سلامت و كيفيت زندكى بيماران مبتلا به آرتريت روماتوئيد مىشود. انجام رفتارهاى خود

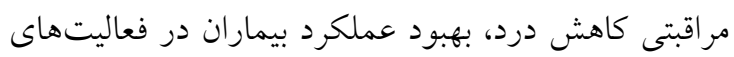

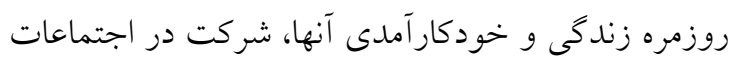
و برقرارى ارتباط با مردم را در يیى داشت كه درد نهايت وضعيت كلى عملكرد بيماران را ارتقاء مىبخشد (ب7). arvidson

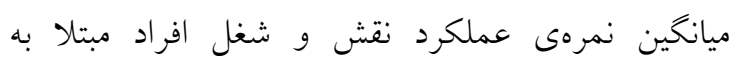

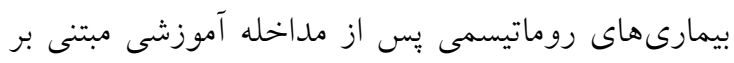

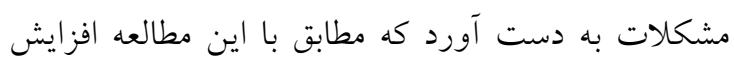
ميانخين را نشان مىداد ولى از نظر آمارى معنىدار نبود.

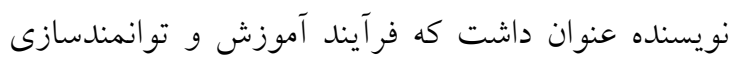

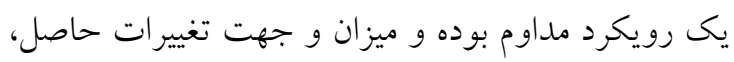

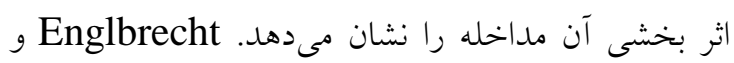

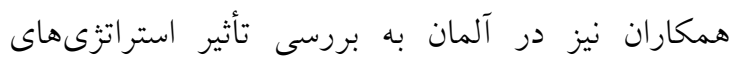
سازكارى و مقابله با مشكلات روانى ناشى از بيمارى 


$$
\begin{aligned}
& \text { اين مقاله منتج از پِايان نامه دانشجوى كارشناسى ارشد }
\end{aligned}
$$

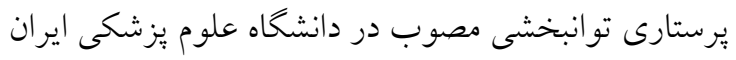

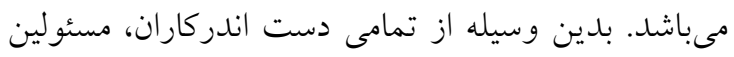

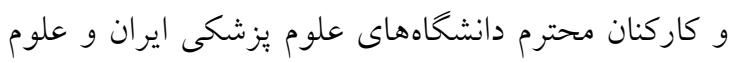

$$
\begin{aligned}
& \text { يزشكى مشهد، مسئولين بيمارستان امام رضا (ع) و قائم } \\
& \text { (عج) شهر مشهد كمال تشكر را داريم. }
\end{aligned}
$$$$
\text { تضاد منافع: هيج گونه تعارض منافع از سوى نويسندكان }
$$

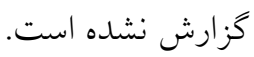

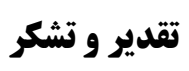

\section{References}

1. Moghadam MH, Jahanbin I, Nazarinia MA. The effect of educational program on self-efficacy of women with rheumatoid arthritis: a randomized controlled clinical trial. International journal of community based nursing and midwifery. 2018;6(1):12-20. [Persian]

2. Khoja SS, Moore CG, Goodpaster BH, Delitto A, Piva SR. Skeletal muscle fat and its association with physical function in rheumatoid arthritis. Arthritis care \& research. 2018;70(3):333-42.

3. Naqvi AA, Hassali MA, Aftab MT, Naqvi SB, Zehra F, Ahmad R, Ahmad N. Development of evidencebased disease education literature for Pakistani rheumatoid arthritis patients. Diseases. 2017;5(4):27.

4. Akhlaghi M, Askarishahi M, Sabzmakan L. Quality of life and related factors in rheumatoid arthritis patients. Journal of health research in community. 2016;2(3):1-11.

5. Ebrahimi M, Moghadamnia M, Farmanbar R, Zayeni SH, Kazem Nejad Leili E. Status of self-care ability of patients with Rheumatoid Arthritis. Journal of Holistic Nursing And Midwifery. 2015;25(4):9-18.

6. Abbasi M, Mousavi MJ, Jamalzehi S, Alimohammadi R, Bezvan MH, Mohammadi H, Aslani S. Strategies toward rheumatoid arthritis therapy; the old and the new. Journal of cellular physiology. 2019;234(7):10018-31. [Persian]

7. Lee SJ, Kavanaugh A. Pharmacological treatment of established rheumatoid arthritis. Best practice \& research Clinical rheumatology. 2003;17(5):811-29.

8. Conigliaro P, Triggianese P, De Martino E, Fonti GL, Chimenti MS, Sunzini F, Viola A, Canofari C, Perricone R. Challenges in the treatment of rheumatoid arthritis. Autoimmunity reviews. 2019;18(7):706-13.

9. Salehi Z, Norouzi Tabrizi K, Hoseini MA, Sedghi Goyaghaj N, Soltani PR. The study of the correlation between medication adherence and quality of life of Rheumatoid Arthritis patients. Journal of Clinical Nursing and Midwifery. 2017;4(3). [Persian]

10. Arvidsson S, Bergman S, Arvidsson B, Fridlund B, Tingström P. Effects of a self-care promoting problem-based learning programme in people with rheumatic diseases: A randomized controlled study. J Adv Nurs. 2013;69(7):1500-14.

11. Ryu JS, Park SH, Seong MH. Factors influencing self-care competence in Korean women with rheumatoid arthritis. J Nurs Res. 2019;27(2):e16.

12. Saeedifar ES, Memarian R, Fatahi S, Ghelichkhani F. Use of the Orem self-care model on pain relief in women with rheumatoid arthritis: a randomized trial. Electronic physician. 2018;10(6):6884.

13. Kordasiabi MC, Akhlaghi M, Baghianimoghadam MH, Morowatisharifabad MA, Askarishahi M, Enjezab B, Pajouhi Z. Self management behaviors in rheumatoid arthritis patients and associated factors in Tehran 2013. Global J Health Sci. 2016;8(3):156.

14. Lopez-Olivo MA, Ingleshwar A, Volk RJ, Jibaja-Weiss M, Barbo A, Saag K, Leong A, SuarezAlmazor ME. Development and pilot testing of multimedia patient education tools for patients with knee osteoarthritis, osteoporosis, and rheumatoid arthritis. Arthr Care Res. 2018;70(2):213-20.

15. Breedland I, van Scheppingen C, Leijsma M, Verheij-Jansen NP, van Weert E. Effects of a groupbased exercise and educational program on physical performance and disease self-management in rheumatoid arthritis: a randomized controlled study. Physical therapy. 2011;91(6):879-93.

16. Vermaak V, Briffa NK, Langlands B, Inderjeeth C, McQuade J. Evaluation of a disease specific rheumatoid arthritis self-management education program, a single group repeated measures study. BMC musculoskeletal disorders. 2015;16(1):1-7.

17. Memarian R, Vanaki Z. The effect of implementing clinical supervision model on the patient education outcomes. Journal of Health Promotion Management. 2012;1(3):28-36. [Persian] 
18. Ndosi M, Johnson D, Young T, Hardware B, Hill J, Hale C, Maxwell J, Roussou E, Adebajo A. Effects of needs-based patient education on self-efficacy and health outcomes in people with rheumatoid arthritis: a multicentre, single blind, randomised controlled trial. Ann Rheum Dis. 2016;75(6):1126-32.

19. Dahmardeh H, Vagharseyyedin SA. Effect of Orem-based self-care education program on diseaserelated problems in patients with multiple sclerosis: A clinical trial. Medical-Surgical Nursing Journal. 2017;6(1):14-20.

20. Keshtkaran Z, Ghodsbin F, Solouki S, Razeghi M, Zare N. The impact of self care education on quality of life of those clients suffering from osteoarthritis in rehabilitation centers of Shiraz University of Medical Science (Iran). Journal Of Babol University Of Medical Sciences (JBUMS). 2010;12(54):65-70. [Persian]

21. Kroon FP, van der Burg LR, Buchbinder R, Osborne RH, Johnston RV, Pitt V. Self-management education programmes for osteoarthritis. Cochrane database of systematic reviews. 2014(1).

22. Armour M, Parry K, Al-Dabbas MA, Curry C, Holmes K, MacMillan F, Ferfolja T, Smith CA. Self-care strategies and sources of knowledge on menstruation in 12,526 young women with dysmenorrhea: A systematic review and meta-analysis. PLoS One. 2019;14(7):e220103.

23. Mirzaei-Alavijeh M, Karami-Matin B, Hosseini SN, Jalilian F. Social Cognitive Determinants of Patient Education Intention among Nurses. J Educ Community Health. 2017;4(1):12-9.

24. Grønning K, Skomsvoll JF, Rannestad T, Steinsbekk A. The effect of an educational programme consisting of group and individual arthritis education for patients with polyarthritis - a randomised controlled trial. Patient Educ Couns. 2012;88(1):113-20.

25. Culha I, Kosgeroglu N, Bolluk O. Effectiveness of self-care education on patients with stomas. $J$ Nurs Health Sci [Internet]. 2016;5:70-6.

26. Mahmoudzadeh-Zarandi F, Hamedanizadeh F, Ebadi A, Raiesifar A. The effectiveness of Orem's self-care program on headache-related disability in migraine patients. Iranian journal of neurology. 2016;15(4):240. [Persian]

27. Halmo R, Galuszka J, Langova K, Galuszkova D. Self care in patients with chronic heart failure. Pilot study-self care includes problems. Biomedical Papers. 2015;159(1):124-30.

28. Shahsavari H, Matory P, Zare Z, Taleghani F, Kaji MA. Effect of self-care education on the quality of life in patients with breast cancer. J Educ Health Prom. 2015;4.

29. Camicia M, Black T, Farrell J, Waites K, Wirt S, Lutz B. The essential role of the rehabilitation nurse in facilitating care transitions: a white paper by the association of rehabilitation nurses. Rehabil Nurs J. 2014;39(1):3-15.

30. Vahedian AA, Alhani F, Hedayat K. Barriers And Facilitators Of Patient's Education: Nurses'perspectives. Iranian Journal of Medical Education. 2012;11(6):620-34. [Persian]

31. Vaughn S, Mauk KL, Jacelon CS, Larsen PD, Rye J, Wintersgill W, Cave CE, Dufresne D. The competency model for professional rehabilitation nursing. Rehabilitation Nursing. 2016;41(1):33-44.

32. Habibzadeh F, Ahmadi,F. Evaluation the effect of self care program designed on the status of activities of daily living in patients with hemorrhagic stroke. Shahed Universuity Scientific Journal 2007. [Persian]

33. Masoudi R, Kheiri F, Ahmadi F, Mohammadi E. The effect of self-care program base on the Orem frame work on fatigue and activity of daily living in multiple sclerosis patients. Archives of Rehabilitation. 2009;10(3). [Persian]

34. Eghlidi J, Mirshoja MS, SHafiei ZA, Jamebozorgi AL, Taghizade G. The effect of sensory-motor training on recovery of basic and instrumental activity of daily living in chronic stroke patients. Scientific Journal of Rehabilitation Medicine. 2015;4(2):79-85. [Persian]

35. Da Silva JA, Phillips S, Buttgereit F. Impact of impaired morning function on the lives and wellbeing of patients with rheumatoid arthritis. Scand J Rheumatol. 2011;40(sup125):6-11.

36. Englbrecht M, Gossec L, DeLongis A, Scholte-Voshaar M, Sokka T, Kvien TK, Schett G. The impact of coping strategies on mental and physical well-being in patients with rheumatoid arthritis. InSeminars in arthritis and rheumatism. 2012; 41(4):545-55. WB Saunders.

37. Nadrian H, Morowatisharifabad MA, SoleimaniSalehabadi H. Paradims of rheumatoid arthritis patients quality of life predictors based on path analysis of the Precede model. Hormozgan Medical Journal. 2010;14(1):32-44. [Persian] 